\title{
Effectiveness of Augmented Reality in Online Distance Learning at the Time of the COVID-19 Pandemic
}

\author{
https://doi.org/10.3991/ijet.v16i09.17895 \\ Amany Ahmed Eldokhny (四) \\ Ain Shams University, Cairo, Egypt \\ amany.eldokhnyesedu.asu.edu.eg
}

Amr Mohammed Drwish

Helwan University, Cairo, Egypt

\begin{abstract}
The current study seeks to investigate the effectiveness of augmented reality in online distance learning at the time of the COVID-19 pandemic. The study was carried out in an instructional software authoring tools course for instructional technology department students to develop academic achievement and instructional software design skills. To achieve this, augmented reality was used, which allowed the learning process to be completed via online distance learning. Forty students were selected to participate by purposeful sampling. The results show that augmented reality was more effective in supporting academic achievement as well as skills acquisition in the virtual classrooms compared to the virtual classrooms that did not use augmented reality in online distance learning. In general, augmented reality or one of its (fixed, animated) patterns can be used to effectively learn in online distance learning during pandemic periods. Also augmented reality that can use location-aware or visionbased may have a good potential in online distance learning within the pandemic. As such the teachers must be prepared to employ all patterns of augmented reality in traditional online distance learning or during the pandemics to achieve the need for 21st-century skills. Conducting more research is required in online distance learning by using augmented reality with another sample and different content general, augmented reality or one of its (fixed, animated) patterns can be used to effectively learn in online distance learning during pandemic periods.
\end{abstract}

Keywords - Distance education, e-learning, blended learning, augmented reality, virtual classrooms, mobile learning, higher education, instructional software design skills, COVID-19 pandemic, King Faisal University, Saudi Arabia

\section{Introduction}

Current technological progress has advanced with the emergence of modern technologies, such as augmented reality (AR) that can integrate images of the virtual world with the real world through its reader. The increasing effectiveness of employing computer applications in different learning environments allows students to work 
on engagement in more realistic experiences, in particular, by having a large number of moving and static images that represent the real world, which in turn increases the mental perceptions of learners [42] [10] [29] [23]. This is because it allows for interactions in the real world by linking realistic goals with 3D images and graphics [46]. Consequently, AR learning environments not only increase the knowledge structure of learners, but also provide them with a good way to engage in those environments to gain an advanced level of experience [26] [15] [43].

AR technology is known as the technology that increases the sense of realism by incorporating digital images and information into the real environment [13] It is not only a virtual technology, but also is designed according to specific features that enable the user to see information at the right time and place [24]. AR can present facts with time and spatial obstacles more effectively; specifically, it increases the motivation towards learning and has an impact on learning outcomes and performance [48]. Moreover, this augmentation process fulfills the dreams of teachers in ubiquitous learning, and learners have been able to develop their own and continuous knowledge [47].

Many researchers in the field of AR have emphasized its positive effects in the learning environment in terms of providing engagement and motivation for students towards learning and helping students to gain experiences by repetition of situations that are difficult to repeat in reality. It is also beneficial for teaching subjects in which it is difficult for students to acquire skills due to their seriousness or scarcity. Furthermore, AR increases collaboration and cooperative learning among students, on the one hand, and between students and the teacher on the other hand, developing the students' creativity and spatial imagination, helping them to control their learning according to their preferred learning style, and enabling teachers to create learning environments suitable for students' cognitive styles [28] [23].

The scope of the current problem is determined by the fact that the data-collection environment was created by the COVID-19 pandemic, which caused schools to suspend study and apply full lockdowns, converting the entire learning process to online distance learning. Likewise, the course where data were collected a course on instructional software design at King Faisal University in Saudi Arabia was of a practical nature and required students to acquire instructional software design skills using instructional software authoring tools. This was to be completed in a practical and applied way, and the students were presented with a practical statement before the inperson meetings were suspended. Thus, the current study adapted to the use of AR technology in the virtual classrooms via online distance learning that enabled data collection to proceed long-distance. where that it took 9 weeks during the second term while classes were sus-pended due to the pandemic from March 9 to May 14, 2020. 


\section{$2 \quad$ Literature Review}

\subsection{Augmented Reality}

Many studies have explored AR and its effectiveness such as Annetta et al. [5]; Bressler and Bodzin [11]; and Enyedy et al. [21]. Some have researched the effect of AR on cognitive performance through educational games, including Arvanitis et al. [6], who examined its effects on students with physical disabilities in learning science. Furthermore, Morrison et al. [34] examined the AR impact through several educational applications designed to read paper maps. All of these studies unanimously agreed on the great potential for augmented reality and its positive impact on the various learning outcomes, regardless of the nature of the target sample (e.g., whether they were samples of traditional learners or those with learning disabilities).

Moreover, some studies that employed AR noted its significant results in learning. For example, Billinghurst and Dunser [9] examined the effects of AR in the classroom and clarified the benefits of using AR in scholarly textbooks. They were most interested in how this technology can increase the potential benefits of the educational environment and the development of student learning, and they relied on the fact that AR works by helping to complete educational courses, not to replace them. The study was based on two groups of students, those with low and high reading ability, who studied a social studies book with AR pictures. The results showed that learning was more effective among the AR group than the control group. It certainly has a bigger and more influential role when it is used to help students read complex social studies concepts. Similar studies were also conducted by Cooperstock [19]; Shelton and Hedley [42]; Klopfer and Squire [29]; and Liou et al. [32] in the same field. In general, these studies dealt with AR in several ways, either according to the content or the courses it provides, the type (fixed or animated in the form of an educational application), or the technology through which it was designed (vision-based or locationaware). Most stated that it is useful when applied in e-learning environments.

The current study highlights the importance of employing AR in online distance learning during the COVID-19 pandemic to test its effectiveness in academic achievement and acquisition of instructional software design skills.

\subsection{Online Distance Learning}

Online distance learning (ODL) is defined as how the learning process is delivered to the distance learner via the Internet, where the teacher interacts with the learners virtually and not face-to-face [31]. ODL is defined idiomatically as e-learning. Furthermore, if it is well designed, it helps to achieve learning outcomes accurately and effectively. One of the most important features of ODL that contributed greatly to its introduction to university education on a large scale is the ability to provide education flexibly and effectively, taking into account the suitability of its cost for all levels of students [44]. According to a study by Saykili [40], this feature also made AR one of the best technological innovations that can be incorporated into ODL. Furthermore, 
Lytridis et al. [33] have shown that when incorporating AR within ODL, this guides students to self-study and stimulates independent learning. Coffin et al. [17] also explained how to enrich virtual classrooms in ODL by educational AR applications to add comments and explanations to realistic educational models.

Many of the studies related to the field of ODL are focused on a comparison between it and the traditional classrooms and its effectiveness in achieving various learning outcomes [35] [14]. They mention that, compared to ODL, sometimes the traditional classrooms were superior in increasing student academic achievement, and other times there were significant advantages for ODL in increasing student achievement. Several other studies also agreed that a good design for the ODL environment is the main factor in its success and achieving learning outcomes, such as achievement and skills, which is linked to several criteria (institutional management, learning environment, educational design, training, technical support and assessment of the course). On the other hand, the nature of the content and the appropriateness of its procedures for learning through ODL is also important. In this regard, studies of Hughes et al. [25]; Patrick and Powell [37] have shown that the effectiveness of both virtual classrooms and virtual schools through e-learning in general increased student academic achievement and skills. This is consistent with a study by Barbour and Mulcahy [7], who investigated the role of virtual classrooms in ODL in increasing the academic achievement and skills of high school students who live in remote places compared to their colleagues who study in traditional classrooms. The results indicated that these students outperform their peers in academic achievement and skills at the level of all courses. Considering these issues, the current study used ODL; it was especially helpful because it is compatible with employing AR in an education setting and under the circumstances created by the pandemic.

\subsection{The COVID-19 pandemic}

COVID-19 is a disease caused by a novel coronavirus (SARS-CoV-2) that emerged in China in late 2019. Coronaviruses are known as "a group of related viruses that cause diseases in mammals and birds. In humans, coronaviruses cause respiratory tract infections that can range from mild to lethal" [41]. SARS-CoV-2 began to spread in the Kingdom of Saudi Arabia in March 2020 when the first case was detected in the eastern province of the Kingdom; the number of cases rose to 17 by March 14 , resulting in the suspension of university and classroom study in all parts of the Kingdom, starting with the full lockdown on March 8. The whole process of learning transferred to ODL across the country. At King Faisal University, all faculty were asked to upload the entire contents of their courses digitally and to set specific mechanisms for their implementation in terms of defining activities, short tests, reports, and assignments that students would be assigned, in addition to setting virtual classroom times accurately. There was follow-up daily from the college department for academic affairs about the course of ODL and weekly follow-up to eliminate the difficulties that may be faced by students and teachers. Several online training courses on the use of the learning management system (LMS), Blackboard, were provided for university faculty who needed to develop their skills in its use. This may be consistent with 
many studies conducted lately in the field of ODL, as Cheawjindakarn et al. [14]; and Alturise [3] whose stated to the need for continuous follow-up of ODL processes via Blackboard, such as training and technical support, which were considered one of the most important criteria for the success of ODL in higher education.

Each professor was able to decide whether or not to follow their students on the social media tool they preferred, with the need to adhere to the use of Blackboard in the weekly virtual classrooms and performance of tests of all sorts. The current research also relied on the use of Blackboard to teach all aspects of the course, especially the process and practical side, since it provides several tools that enable the course instructor to teach performance skills effectively in front of students by default. This is what was recommended by Chick et al. (2020), who emphasized the need to acquire practical skills through ODL and not to distract the students from learning processes for long periods of time.

In general, the COVID-19 pandemic caused teachers to recognize the use of ODL in a new and more effective way. They searched for the most appropriate ODL strategies and reformulated the tasks assigned to students in ways that could be easily evaluated and monitored for their digital progress. This corresponds exactly to the results of the study of Basilaia and Kvavadze [8], which confirmed that ODL skills that students have used within learning processes during the COVID-19 pandemic will undoubtedly have a positive impact on their abilities and life skills later, especially for graduate students. In total, during the pandemic, the number of synchronous virtual classrooms at King Faisal University through ODL, between March 10 and April 9, reached 34,196; the number of pre-recorded lectures that were available on the system was 113,399 ; the number of teachers at the university was 1,903 ; the number of students was 58,976; and the average number of Blackboard users per day was 31,451 [1].

\section{$3 \quad$ Research Questions and Hypotheses References}

\subsection{Questions}

What is the effectiveness of augmented reality in ODL at the time of the COVID19 pandemic on:

1. Students' academic achievement?

2. Students' instructional software design skills?

\subsection{Hypothesis}

Hypothesis 1: There are statistically significant differences $(\mathrm{p}<.05)$ in academic achievement between the experimental group (AR in virtual classrooms) and the control group (virtual classrooms without AR) in ODL in favour of the experimental group. 
Hypothesis 2: There are statistically significant differences $(p<.05)$ in instructional software design skills between the experimental group (AR in virtual classrooms) and the control group (virtual classrooms without AR) in ODL in favor of the experimental group.

\section{Methodology}

\subsection{Study approach}

The current study adopted the experimental approach to test the effectiveness of $A R$ in virtual classrooms versus virtual classrooms without AR in ODL at the time of the COVID-19 pandemic. The dependent variables are students' academic achievement and instructional software design skills. As the current study aims to provide different treatment for specific educational tasks, and test the effect resulting from the employment of this experimental treatment, so the experimental approach was adopted, as this study belongs to the category of studies that aims to investigate the causal relationships between variables and test them [2]. as several studies developed in ODL that emphasizes its effectiveness in educated theoretical knowledge to students [25] [37] [38], therefore its ability to overcome the crisis in the pandemic times but it is not a fundamental solution or a unique method in acquiring practical skills for students (specialized\& professional), so the current study directed to use the most appropriate technological innovator that helps in the acquisition and development of the course skills provided that it gives the students the opportunity to acquire those skills in an environment that is close to the characteristics of the physical environment in the traditional classrooms, consequently the current study adopted the AR in teaching the experimental group, according to what It was reviewed by number of studies that mentioned its most valuable characteristics are (engagement, motivation) that helps in achieving the skilful learning outcomes [28] [23] [20].

\subsection{Participant population}

In the College of Education at King Faisal University, 55 male and female Saudi students were enrolled in an undergraduate "instructional software authoring tools" course, are between 19 to 20 years old, belong to the cities and villages of Al-Ahsa Governorate, (one of the governorates of the eastern province), in addition to small number of students from neighbouring governorates, 5 students were excluded because they were experiencing technical problems in communicating with the Internet during the broadcast of simultaneous lectures, as this is a fundamental reason in requesting the college department for academic affairs to prepare the pre-recorded lectures to serve these students. The 50 other students were intentionally selected to participate in the study and were randomly divided into the pilot study (10), the control group (20), and the experimental group (20). 


\subsection{Data collection instrument}

Academic achievement test: An objective test was developed to assess the academic achievement of students by measuring their theoretical knowledge about the instructional software authoring tools course. The test consisted of 30 single-type multiple-choice questions. Each item was worth one point on the final score. The content of the course was analysed for a set of main tasks and put it in the form of a concept map including the following main concepts: (Instructional software design criteria, Methods of controlling the display, Design of Interaction and navigation process, and Publishing\& use), in light of that the cognitive objectives were set their level, as well as the proposed test vocabulary for each objective separately, then it introducing to several instructional technology experts, as the number of five experts was chosen based on their vast experience in the field of distance learning to calculate the validity of the test, as they were briefed on the purpose of the test, it was intended to measure students' progress in the knowledge and concepts of the course to achieve the academic goals, they were asked to express their views on the suitability of test phrases to measure the cognitive objectives and theoretical aspects of the content, as shown in Table 1. Their opinions came in at $94 \%$ agreement to the integrity of the test phrases and their suitability to what was set to measure, and they recommended making some adjustments to rewrite some of the test items. After that, the test was ready for the pilot sample to calculate statistical validity. After retesting the pilot sample after two weeks, the reliability of the test was calculated. The value was 0.84 , a high value for the reliability of the test, that means that the test can give the same results if it is reapplied to the same sample in the same circumstances and it is free from errors that can change the student's performance, which makes the researchers reassured to use it as a measurement tool. The appropriate time to perform the test was calculated by monitoring the performance time for each student in the retest of the pilot study, then calculating the average performance of the test to whole students, which reached (40) minutes. 
Paper-Effectiveness of Augmented Reality in Online Distance Learning at the Time of the COVID...

Table 1. Learning outcomes, cognitive objectives, and sample for questions of proposed the academic achievement test before introducing it to the experts

\begin{tabular}{|c|c|c|c|c|c|c|}
\hline \multirow{2}{*}{$\begin{array}{l}\text { Concepts/ } \\
\text { learning } \\
\text { outcomes }\end{array}$} & \multirow[t]{2}{*}{ Cognitive objectives } & \multirow[t]{2}{*}{ Level } & \multirow[t]{2}{*}{ Question } & \multicolumn{2}{|c|}{$\begin{array}{c}\text { Relevance to } \\
\text { concepts }\end{array}$} & \multirow{2}{*}{$\begin{array}{c}\text { Suggested } \\
\text { amendments }\end{array}$} \\
\hline & & & & Agree & Disagree & \\
\hline \begin{tabular}{|l|} 
Instructional \\
software \\
design criteria
\end{tabular} & $\begin{array}{l}\text { - List the technical } \\
\text { criteria for instructional } \\
\text { software design. }\end{array}$ & Identify & $\begin{array}{l}\text { 1- All the following } \\
\text { technical criteria for } \\
\text { instructional software } \\
\text { design except: } \\
\text { - Free from programming } \\
\text { errors. } \\
\text {-Screen design. } \\
\text {-Ease and flexibility of } \\
\text { using the software. } \\
\text { - draw attention. }\end{array}$ & & & \\
\hline \begin{tabular}{|l|} 
Design of \\
Interaction \\
and navigation \\
process
\end{tabular} & $\begin{array}{l}\text { - Analyses the structural } \\
\text { properties of the instruc- } \\
\text { tional software. }\end{array}$ & $\begin{array}{l}\text { Ana- } \\
\text { lyse }\end{array}$ & $\begin{array}{l}\text { 2- The transitions via } \\
\text { buttons between the } \\
\text { instructional software } \\
\text { screens that you designed } \\
\text { in the instructional soft- } \\
\text { ware authoring tool. The } \\
\text { instruction expresses an } \\
\text { advantage: } \\
\text { - Interconnection of } \\
\text { information } \\
\text { - Constructivism. } \\
\text { - Integrative. } \\
\text { - Interactive. }\end{array}$ & & & \\
\hline
\end{tabular}

Skill performance observation card: The current study aims to examine how computer teacher program students obtain the skills of instructional software design using AR through ODL. Accordingly, the course was adopted Authorware software v. 0,7 from Macromedia developer to train students to design instructional software (see Figure 1).

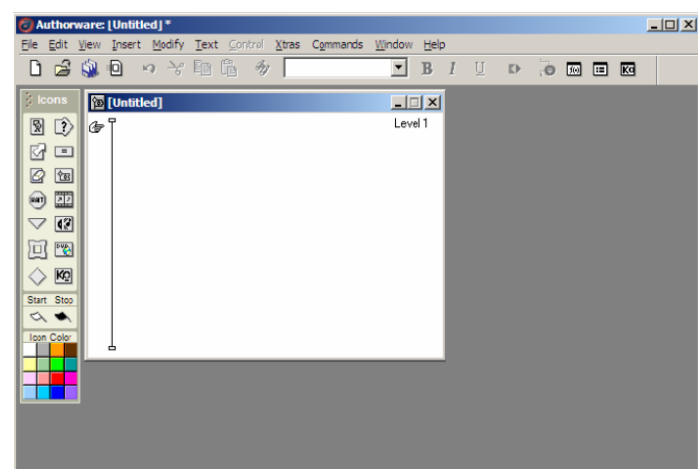

Fig. 1. Authoreware software v. 0.7 
A list of behavioural objectives was set for the instructional software authoring tools course. The preliminary list of behavioural objectives was presented to several judges of instructional technology, and the percentage agreement among them on the validity of the list $(98 \%)$ came with the suggestion of some minor amendments. Consequently, a list of instructional software design skills was drawn up, and the number of basic skills was 10 , sub-skills was 14 , and performance skills was 62 . This served as the full skill performance observation card. The study also adopted a 5-point Likert system to estimate the students' scores in the skill performance observation card $($ Novice $=1$; Emerging $=2$; Developing $=3$; Proficient $=4$; Expert $=5)$. The score for the card ranged from 62 (the lowest score) to 310 points (the highest score). The validity of the card was calculated by introducing it to the same mentioned experts before of instructional technology. While they requested some modifications to paraphrase some of the paragraphs for further clarification, the reliability of the skill performance observation card was calculated using the Spearman correlation coefficient after applying it to the pilot sample, which reached .93 , indicating a high-reliability rate. The score of each student was recorded in the skill performance observation card after sending individual works for each of them separately via the Blackboard and researchers evaluating the level of performance, giving a degree under the appropriate according to the 5-point Likert system. As the student's performance is simple, he will be evaluated as a novice, and one point will be monitored for the performance skill separately, if his performance is professional, he will be evaluated as an expert and five-point will be monitored, as shown in Table 2. then the total score of the student points in the card will be calculated.

Table 2. Instructional software design skills to be learned through the ODL using AR

\begin{tabular}{|l|l|l|}
\hline \multicolumn{1}{|c|}{ Basic skill } & \multicolumn{1}{|c|}{ Sub-skill } & \multicolumn{1}{|c|}{ Performance skill } \\
\hline $\begin{array}{l}\text { Instructional software } \\
\text { background design }\end{array}$ & Insert the display icon & $\begin{array}{l}\text { Pull out the display icon } \\
\text { Re-name } \\
\text { Import a background image } \\
\text { Resize and adjust the image } \\
\text { Use the text tool to add different texts to the background } \\
\text { Set font settings from the mode's icon on the toolbar } \\
\text { Set font settings from the Text menu } \\
\text { Adjust the effects settings for the display icon from proper- } \\
\text { ties then Transition }\end{array}$ \\
\hline Use the wait icon & Insert the wait icon & $\begin{array}{l}\text { Pull out the Wait icon } \\
\text { Re-name } \\
\text { Set the settings for the appearance of the wait icon from } \\
\text { properties then Transition } \\
\text { Differentiate between using the settings of events, time } \\
\text { limit, options }\end{array}$ \\
\hline Use the erase icon & Insert the erase icon & $\begin{array}{l}\text { Pull out the erase icon } \\
\text { Re-name } \\
\text { Adjust settings for the appearance of the erase icon from } \\
\text { properties then Transition } \\
\text { Differentiate between icon to erase and icon to preserve } \\
\text { from the menu of the list }\end{array}$ \\
\hline Use the audio file & $\begin{array}{l}\text { Pull out the sound icon } \\
\text { Re-name } \\
\text { Use the import icon to insert sound from properties }\end{array}$ \\
\hline
\end{tabular}




\begin{tabular}{|c|c|c|}
\hline Basic skill & Sub-skill & Performance skill \\
\hline & & $\begin{array}{l}\text { Adjust sound settings from the sound and timing tab in the } \\
\text { properties window }\end{array}$ \\
\hline Animation design & Insert the motion icon & $\begin{array}{l}\text { Pull out the motion icon } \\
\text { Re-name } \\
\text { Draw one of the shapes of animations and specify different } \\
\text { paths of movement for them }\end{array}$ \\
\hline Use the map icon & Insert the map icon & $\begin{array}{l}\text { Pull out the map icon } \\
\text { Re-name } \\
\text { Grouping of software icons } \\
\text { Ungrouping the software icons } \\
\text { Learn the grouping and ungrouping command from the } \\
\text { modify menu }\end{array}$ \\
\hline $\begin{array}{l}\text { Use the calculation } \\
\text { icon }\end{array}$ & $\begin{array}{l}\text { Insert the calculation } \\
\text { icon }\end{array}$ & $\begin{array}{l}\text { Pull out the calculation icon } \\
\text { Re-name } \\
\text { Open the calculation icon and write the code going to a } \\
\text { specific page in the software }\end{array}$ \\
\hline $\begin{array}{l}\text { Use the navigation } \\
\text { icon }\end{array}$ & $\begin{array}{l}\text { Insert the navigation } \\
\text { icon }\end{array}$ & $\begin{array}{l}\text { Pull out the calculation icon } \\
\text { Re-name } \\
\text { Connect the navigation tool to the interaction tool } \\
\text { Set the settings for the previous and next buttons through } \\
\text { the navigation tool }\end{array}$ \\
\hline \multirow{5}{*}{$\begin{array}{l}\text { Use the interaction } \\
\text { icon }\end{array}$} & $\begin{array}{l}\text { Insert the interaction } \\
\text { icon/button }\end{array}$ & $\begin{array}{l}\text { Pull out the interaction icon } \\
\text { Re-name } \\
\text { Link display icon within the interaction icon } \\
\text { Choose the type of reaction button } \\
\text { Set the button interaction settings from the response within } \\
\text { the properties } \\
\text { Adjust the settings of the button from the button inside the } \\
\text { properties }\end{array}$ \\
\hline & $\begin{array}{l}\text { Insert the interaction } \\
\text { icon/keypress }\end{array}$ & $\begin{array}{l}\text { Pull out the interaction icon } \\
\text { Re-name } \\
\text { Link display icon within the interaction icon } \\
\text { Choose the type of interaction keypress } \\
\text { Set the settings for the keypress interaction from the re- } \\
\text { sponse within the properties }\end{array}$ \\
\hline & $\begin{array}{l}\text { Insert the interaction } \\
\text { icon/text entry }\end{array}$ & $\begin{array}{l}\text { Pull out the interaction icon } \\
\text { Re-name } \\
\text { Link display icon within the interaction icon } \\
\text { Choose the text entry type } \\
\text { Set the text entry reaction settings from the response within } \\
\text { the properties }\end{array}$ \\
\hline & $\begin{array}{l}\text { Insert the interaction } \\
\text { icon/hot spot }\end{array}$ & $\begin{array}{l}\text { Pull out the interaction icon } \\
\text { Re-name } \\
\text { Link display icon within the interaction icon } \\
\text { Choose a hot spot } \\
\text { Set hot spot reaction settings from response within proper- } \\
\text { ties }\end{array}$ \\
\hline & $\begin{array}{l}\text { Insert interaction } \\
\text { icon/hot object }\end{array}$ & $\begin{array}{l}\text { Pull out the interaction icon } \\
\text { Re-name } \\
\text { Link display icon within the interaction icon } \\
\text { Choose the hot object type } \\
\text { Set the settings for the hot object interaction from the } \\
\text { response within the properties }\end{array}$ \\
\hline Export the project & $\begin{array}{l}\text { Using the publish } \\
\text { command }\end{array}$ & $\begin{array}{l}\text { Set the publish setting to export the project in the form of } \\
\text { the instructional software }\end{array}$ \\
\hline
\end{tabular}




\subsection{Procedure}

The researchers made a booklet for students enrolled in the seventh level of the computer teacher program, linked with an application that was uploaded on the smart devices (mobiles, tablets), which presented basic and performing skills for the instructional software authoring tools course. Introduced to the same five experts to evaluate it in terms of processing of the content via AR. A set of images were included to explain the performing skills for the course that allowed students to review their content. With the AR, students passed the mobile camera over these images, which reads the data linked to these images from the AR database loaded on the application, reviewed their content through several serial pictures, and pre-prepared instructional video clips that explained how to perform these skills in order. The open-source software, HP REVAl, was used to produce the static AR images, and the unity program was used to produce the AR videos.

This booklet was made available to students of the experimental group in the virtual classrooms in ODL during the period of suspension of study due to the COVID-19 pandemic. In contrast, the skills for the instructional software authoring tools course for the students of the control group were studied in the virtual classrooms but without using the AR; these students were only provided the virtual lectures according to the following steps:

- The students were divided into two groups: experimental and control.

- The virtual classroom was set weekly via Blackboard for each group separately.

- Many sources were made available for both groups in the instructional course via Blackboard.

The control group was provided with the course plan through the Blackboard plan icon, with a note of each procedure. In this plan the study subjects for the course were explained and what is required of each student to perform weekly reports or duties and dates of submission and the links that It can be used to enrich the knowledge and skill aspects of the course. The control group started to communicate via the virtual classroom by a pre-recorded lecture and simultaneously to define their tasks with the teacher to learn the specified skills by listing and viewing the explanation via Blackboard. A number of pre-prepared videos were also available, allowing students to view the performance skills any number of times in order to be able to master the instructional software design skills, Where the researchers set it up and made it available on the Blackboard in the course content icon (the same videos that were also used with the experimental group in the augmented reality animated type), traditional discussion tools (forums) were used with virtual classrooms in ODL to allow interaction and free discussion with the teacher on topics that need further clarification.

The experimental group was provided with the course plan through the Blackboard plan icon, with a note of each procedure. In this plan the study subjects for the course were explained and what is required of each student to perform weekly reports or duties and dates of submission and the links that It can be used to enrich the knowledge and skill aspects of the course. The experimental group started to communicate via the virtual classroom by a pre-recorded lecture and simultaneously to 
define their tasks with the teacher to learn the specified skills by using the booklet that was designed via AR. Students were able to move the mobile camera all over the picture in the booklet; then they saw the sequence of images or videos for the instructional software design skills and could repeat it as many times as they wanted, traditional discussion tools (forums) were used with virtual classrooms in ODL to allow interaction and free discussion with the teacher on topics that need further clarification (see Figure 2).

Both researchers were available to support and assist students and eliminate any difficulties they encountered when needed.

The assessment using the academic achievement post-test involved using exam tools in Blackboard simultaneously. The test settings were set in terms of time and options to send the answers via Blackboard in ODL to avoid re-testing for the same student and to reduce the chances of cheating.

The assessment using the skill performance observation card was carried out once the experiment was completed. Students were provided with a skill performance observation card for instructional software design skills during the virtual classroom and were asked to perform the required skills in order. After completing the performance of all skills on the card, each student sent their work individually through Blackboard.

The procedures for applying the experiment took 9 weeks during the second term while classes were suspended due to the pandemic-from March 9 to May 14, 2020.

Statistical and analytical processes were performed appropriate for the data collected for the academic achievement test and the skill performance observation card to test the hypotheses. Independent sample t-tests were used to examine the differences between the mean scores of the control and experimental groups (AR in virtual classrooms vs. virtual classrooms without AR).

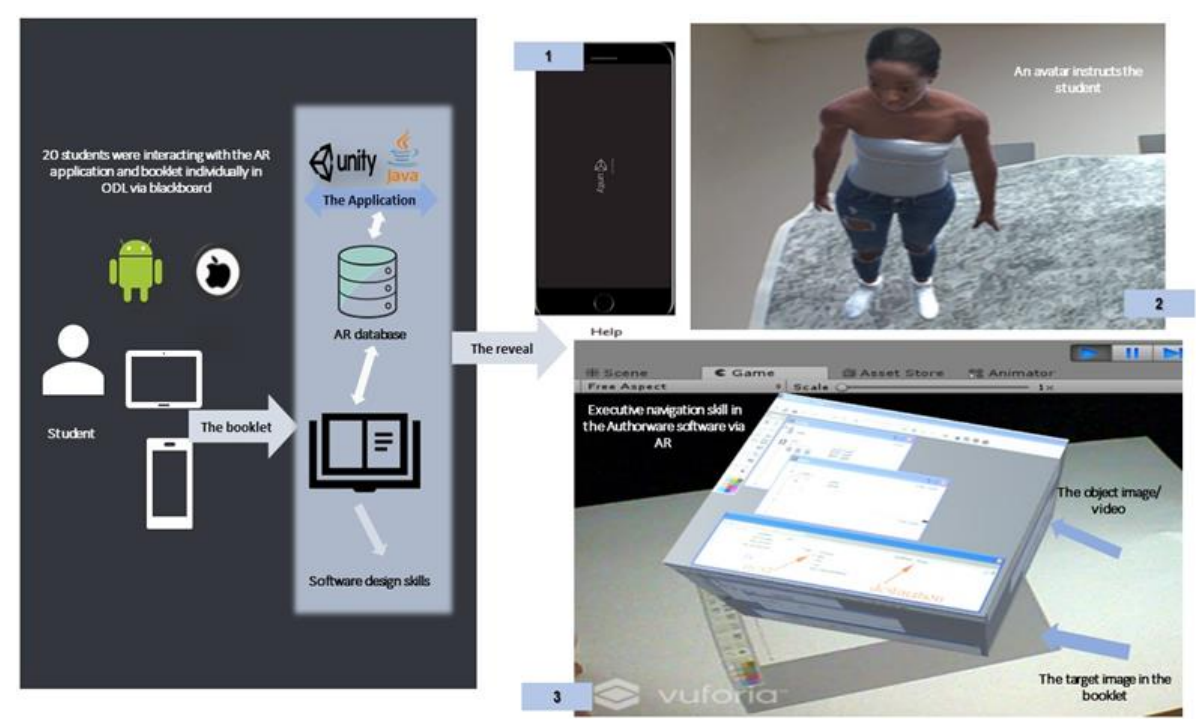

Fig. 2. Experimental group processing 


\section{$5 \quad$ Results and Discussion}

The statistical analysis software SPSS version 22 was used for analysis of the data. To identify the effectiveness of AR in ODL, independent samples t-tests were used.

\subsection{Homogeneity between the two groups}

Table 3 shows the homogeneity of the control and experimental groups before proceeding with the experiment. The results of independent samples t-tests of the achievement scores of both groups show that there are no significant differences between the control group $(\mathrm{M}=12.40 ; \mathrm{SD}=2.82)$ and the experimental group $(\mathrm{M}=$ $12.20 ; \mathrm{SD}=3.16)$ in the achievement pre-test $(\mathrm{t}(38)=.21 ; \mathrm{p}=.732)$. Both groups were homogeneous before proceeding to the research experiment.

Table 3. Independent samples t-test for the research groups on achievement (pre-test)

\begin{tabular}{|l|c|c|c|c|c|c|}
\hline \multicolumn{1}{|c|}{ Group size } & N & Mean & SD & DF & T & Sig. \\
\hline Control & 20 & 12.40 & 2.82 & \multirow{2}{*}{38} & .21 & .732 \\
\hline Experimental & 20 & 12.20 & 3.16 & & & \\
\hline
\end{tabular}

\subsection{Academic achievement}

Table 4 shows the means and standard deviations for the control and experimental groups and the results of the t-test of the two groups' scores in the academic achievement post-test, where the findings showed that there were significant differences between the control group $(M=27.50 ; S D=1.15)$ and experimental group $(M=28.60$; $\mathrm{SD}=0.60)$ in the academic achievement post-test $(\mathrm{t}(38)=-3.80 ; \mathrm{p}<.001)$ in favour of the experimental group. Accordingly, the first hypothesis was supported.

Table 4. Independent samples t-test for both research groups on academic achievement (post-test)

\begin{tabular}{|l|c|c|c|c|c|c|}
\hline \multicolumn{1}{|c|}{ Group size } & N & Mean & SD & DF & T & Sig. \\
\hline Control & 20 & 27.50 & 1.15 & \multirow{2}{*}{38} & -3.80 & .001 \\
\hline Experimental & 20 & 28.60 & .60 & & & \\
\hline
\end{tabular}

\subsection{Instructional software design skills}

Table 5 shows the means and standard deviations for both the control and experimental groups and the independent samples t-tests of the two groups' scores in the skill performance observation card post-test, where the results showed that there were significant differences between the control group $(\mathrm{M}=305.50 ; \mathrm{SD}=2.59)$ and experimental group $(\mathrm{M}=307.40 ; \mathrm{SD}=1.31)$ in the post-test $(\mathrm{t}(38)=-2.93 ; \mathrm{p}=.002)$ in favour of the experimental group. Accordingly, the second hypothesis was supported. 
Table 5. Independent samples t-test for the research groups on the instructional software design skills

\begin{tabular}{|l|c|c|c|c|c|c|}
\hline \multicolumn{1}{|c|}{ Group Size } & N & Mean & SD & DF & T & Sig. \\
\hline Control & 20 & 305.50 & 2.59 & \multirow{2}{*}{38} & -2.93 & .002 \\
\hline Experimental & 20 & 307.40 & 1.31 & & & \\
\hline
\end{tabular}

\section{Conclusion}

According to the data shown in Tables 3 and 4, it was revealed that members of both the control and experimental groups performed well in the academic achievement test and the skill performance observation card, in general. This is consistent with most studies that confirmed that ODL was effective for the students [35] [15] [25] [37] [7] [4]. However, the results of the statistical analysis indicated the relatively greater effectiveness of AR in the virtual classrooms in both academic achievement and the acquisition of instructional software design skills for students compared to the virtual classrooms without AR. The researchers offer several explanations for this. The booklet made it easy to view it any number of times using tablets or smartphones, as the researchers made sure that the Application designed with the AR linked to the booklet works on all operating systems for Android and IOS, which led to students mastering the skills of using the Application, thus the acquisition and mastery of instructional software design skills. That is consistent with the conclusion of Coimbra, Cardoso and Mateus [18] that stated that the frequent use of tablet devices in AR applications affects the increased interaction of students with the presented content, as each student seeks to discover the most appropriate way to learn, saved his favourite footage for easy retrieval, that in the future affects his overall performance. On the other hand, the students of the control group had to enter the Blackboard and watch the videos in the content area to acquire and master design skills, that was difficult to $\log$ in at certain times of the day due to the severe pressure on it, that was sure that it negatively affected the number of entry times, that generally influenced their performance later.

According to cognitive load theory, both pre-made pictures and videos in AR have facilitated identifying, distinguishing, and easily recognizing information about the steps and skills of instructional software design for the experimental group students. It enabled students to have a moving, visual and schematic visual sequence within memory, which reduced the burden on their memory and thus helped them to understand the relationships between information and clarity of distinctions, which was positively reflected in their understanding and comprehension of the presented content. This was observed as its effect on increasing the academic achievement of the experimental group students. On the other hand, the control group which was studied according to what is known in ODL from students attending simultaneously virtual classrooms with the teacher or watching them in pre-recorded lectures may have experienced a negative interaction with the teacher and their various learning activities (participation in dialogue forums and discussions on the topic of learning). This could have adversely affected the level of their academic achievement. This finding is con- 
sistent with the results of prior works for Wójcik [46]; Billinghurst and Dunser [9]; Cooperstock [19]; Shelton and Hedley[42]; Klopfer and Squire [29]; Liou et al. [32]; and Nurbekova and Baigusheva [36] that has concluded that AR helps to develop students cognitively and skilfully.

Human voices, comments and soundtracks in video clips, images and animations in AR represented a cognitive anchor for students of the experimental group. They provided useful guidelines in illustrating complex design skills or consisting of sequential and interrelated steps. It has also been used to stimulate the functional behaviours of cognitive systems in students because it stimulates the power of the human visual system to depict dynamic visualizations, which reduce cognitive loads because they are visual stimuli that have a positive effect on learning. Consequently, an instructional video message was presented with a high degree of clarity by making mental connections between visual and verbal representations, which in turn achieved a balance for learning interactions, as it allowed students to repeat their presentation at any time and for an unlimited number of times. This, in turn, reflected on the acquisition and development of students' instructional software design skills. This result is consistent with studies of Wei et al. [45]; Hughes et al. [25]; and Patrick and Powell [37] that have demonstrated the effectiveness of AR on the acquisition and development of skills. On the other hand, we find the control group, which was studied according to the virtual classrooms without using AR, and whose students were allowed to view the recorded lectures an unlimited number of times, did not excel as did the experimental group in the acquisition and development of instructional software design skills, which may be due to two factors.

First, the pre-recorded lectures were not focused only on the performance of the practical skills of the course but were usually addressed to other theoretical topics related to the skills that required explanation. This was unlike the AR lessons, which displayed each image when the student passed the mobile camera to one of the practical skills of the course, and no other material was covered beyond that skill.

The superiority of the experimental group students in achieving the theoretical and cognitive side of the course and its reflection on their academic achievement had a positive impact on their acquisition of design skills. Given the low academic achievement of the control group students compared to the experimental group, this also reflected on their lower acquisition of the course skills for the experimental group.

There were some impressions from experimental group students during the learning process, some of them commented, "Away from the pandemic the practical subjects of the computer teacher program should be transferred to teaching by AR; "It is the best way to master the skills that need visual imagination and the most appropriate way to prepare for practical tests". In light of these comments, we conclude why AR was effective at the level of both academic achievement and instructional software design skills, as it worked to build a strong relationship between the learner's interaction and perceptions about the content, and this is what Eldokhny and Drwish [20] have confirmed that AR works to increase academic achievement and spatial visualization. That was stated by Santos, Chen, Taketomi, Yamamoto, Miyazaki and Kato 
[39] whereas they stated that "We explain that AR incurs three inherent advantages: real-world annotation, contextual visualization, and vision-haptic visualization".

\section{$7 \quad$ Limitations and Future Research}

The current study aimed at exploring the effectiveness of AR in academic achievement and the acquisition of instructional software design skills through ODL, which King Faisal University resorted to during the period of suspension of study due to the COVID-19 pandemic. During this time, students were required to finish their remaining courses through ODL, and the results of this study indicate the superiority of AR in virtual classrooms over virtual classroom lessons that do not use AR.

The current study emphasizes the important role of AR because of its effectiveness in achieving learning outcomes, especially during the pandemic, which is expected to continue for a long time around the world. Adjustment to this "new normal" and the practice of social distancing makes AR one of the most appropriate ODL tools designed and applied professionally and accurately.

Therefore, more research and investigation are required on the types and patterns of AR that can be utilized effectively within various learning environments. Instructors can choose the most appropriate methods in line with the nature of the courses offered and the knowledge and skills to be acquired, developed, or perfected through virtual learning platforms, and with the students enrolled in their course. Accordingly, the current study suggests conducting more research on topics such as the most appropriate AR patterns used with students with learning difficulties or gifted students in ODL environments, or the impact of this technology on different learning outcomes through cooperation or collaborative learning strategies.

There are two limitations that the current study was adopted, academic achievement and instructional software design skills, using the quantitative data to investigate the effectiveness of AR on it in ODl, this is because of the lack of early preparation for the pandemic that occurs in an emergency worldwide, the researchers mainly concerned with achieving the traditional outputs of the course as recommended in the course plan and commitment to their full responsibility to their students in acquiring the knowledge and skills that they enrolled in the program mainly, as including a study of the effect of other qualitative variables need more preparation was required at the sample level, as well as the experimental treatment tool (the booklet), as emphasized Kuzu [30]; Karal and Abdulselam [27]; Fidan and Tuncel [22] that AR studies require a multidisciplinary research team, as they require a lot of work in terms of (preparation, design, implementation, and application development), that requires a lot of time that was not available for the current study that was restricted to 9 weeks (the rest of the semester after suspension the learning). AR qualitative research requires more times, Moreover the advanced AR application needs a high level of physical and software equipment [12], that is certainly not available to students of the current study sample, who have excluded 5 students from them as a result of the weakness of the Internet they have. 
However, we recommend the need to include other qualitative data and research their impacts, such as the gender variable, the geographical distribution of students, or learning styles that may have significance if were used with AR in ODL, especially if the pandemic continues for a long term, the size of larger samples using other types of AR such as Real-world annotation, Vision-haptic visualization, Location-aware, where the current study adopted Contextual visualization due to its integration with the acquisition of instructional software design skills and academic achievement.

\section{Acknowledgement}

The authors acknowledge the Computer Teacher Program students in the seventh level at the Faculty of Education at King Faisal University in the instructional software authoring tools course.

\section{References}

[1] @ KFUniversity (2020, April,10). Entry standards for e-learning and distance education systems in. Retrieved from https://twitter.com/KFUniversity/status/123998750208319 $\underline{0786}$.

[2] Abdelhamid, M., (2005). Scientific research in educational technology. Cairo: The World of Books.

[3] Alturise, F., (2020). Evaluation of the Blackboard Learn Learning Management System for Full Online Courses in Western Branch Colleges of Qassim University, International journal of emerging technologies in learning, 15 (15), 33-51, https://doi.org/10.3991/ijet.v15 $\underline{\mathrm{i} 15.14199}$

[4] Al Mulhim, E. N. \& Eldokhny, A. A. (2020). The impact of collaborative group size on students' achievement and product quality in project-based learning environments, International journal of emerging technologies in learning, 15 (10), 157- 174, https://doi.org/10.3991/ijet.v15i10.12913

[5] Annetta, L., Burton, E. P., Frazier, W., Cheng, R., \& Chmiel, M. (2012). Augmented reality games: Using technology on a budget. Science Scope, 36(3), 54-60. Retrieved from https://www.researchgate.net/publication/277304698.

Arvanitis, T. N., Petrou, A., Knight, J. F., Savas, S., Sotiriou, S., Gargalakos, M., \& Gialouri, E. (2009). Human factors and qualitative pedagogical evaluation of a mobile augmented reality system for science education used by learners with physical disabilities. Personal and Ubiquitous Computing, 13(3), 243-250. http://doi.org/10.1007/s00779-007$\underline{0187-7}$

[6] Barbour, M. K., \& Mulcahy, D. (2008). How are they doing? Examining student achievement in virtual schooling. Education in Rural Australia, 18(2), 63-74. Retrieved from https://digitalcommons.sacredheart.edu/ced fac/161/.

[7] Basilaia, G., \& KQ Dxvavadze, D. (2020). Transition to online education in schools during a SARS-CoV-2 coronavirus (COVID-19) pandemic in Georgia. Pedagogical Research, 5(4), em0060. https://doi.org/10.29333/pr/7937.

[8] Billinghurst, M., \& Dunser, A. (2012). Augmented reality in the classroom. Computers \& Education, 45(7), 56-63. https://doi.org/10.1109/MC.2012.111. 
[9] Billinghurst, M., \& Henrysson, A. (2009). Mobile architectural augmented reality. In X. Wang \& M. Schnabel (Eds.), Mixed Reality in Architecture, Design and Construction (pp. 93-104). Springer Link. https://doi.org/10.1007/978-1-4020-9088-2.

[10] Bressler, D. M., \& Bodzin, A. M. (2013). A mixed methods assessment of students' flow experience during a mobile augmented reality science game. Journal of Computer Assisted Learning, 29(6), 505-517. https://doi.org/10.1111/jal.12008.

[11] Buyukozturk, S., Kilic-Cakmak, E., Akgun, O. E., Karadeniz, S. \& Demirel, F. (2012). Research Methods (Thirteenth Edition). Ankara, Turkey: Begum Academic Publications.

[12] Chang, Y. L., Hou, H. T., Pan, C. Y., Sung, Y. T., \& Chang, K. E. (2015). Apply an augmented reality in a mobile guidance to increase sense of place for heritage places. Educational Technology \& Society, 18(2), 166-178. Retrieved from https://www.jstor.org/stable/pdf/jeductechsoci.18.2.166.pdf?seq=1.

[13] Cheawjindakarn, B., Suwannatthachote, P., \& Theeraroungchaisri, A. (2012). Critical success factors for online distance learning in higher education: A review of the literature. Creative Education, 3, 61-66. https://doi.org/10.4236/ce.2012.38B014.

[14] Chiang, T. H. C., Yang, S. J. H., \& Hwang, G. H. (2014). Students' online interactive patterns in augmented reality-based inquiry activities. Computers \& Education, 78, 97-108. https://doi.org/10.1016/j.compedu.2014.05.006.

[15] Chick, R., Clifton, G., Peace, K., Propper, B., Hale, D., Alseidi, A., \& Vreeland, T. (2020). Using technology to maintain the education of residents during the COVID-19 pandemic. Journal of Surgical Education, 77(4), 729-732. https://doi.org/10.1016/j.jsurg.2020.03.018.

[16] Coffin, C., Bostandjiev, S., Ford, J. \& Hollerer, T. (2010). Enhancing Classroom and Distance Learning Through Augmented Reality. In J. Herrington \& C. Montgomerie (Eds.), Proceedings of ED-MEDIA 2010-World Conference on Educational Multimedia, Hypermedia \& Telecommunications (pp. 1140-1147). Toronto, Canada: Association for the Advancement of Computing in Education (AACE). Retrieved from https://www.learntechlib.org/primary/p/34777/.

[17] Coimbra, M. T., Cardoso, T., \& Mateus, A. (2015). Augmented reality: an enhancer for higher education students in math's learning? Procedia Computer Science, 67, 332-339. https://doi.org/10.1016/j.procs.2015.09.277.

[18] Cooperstock, J. R. (2001). Classroom of the future: Enhancing education through Augmented Reality. In M. J. Smith, G. Salvendy, D. Harris, \& R. J. Koubek (Eds.), Usability evaluation and interface design: Cognitive engineering, intelligent agents and virtual reality: Vol. 2. Proceedings of HCI International 2001 (pp. 688-692). Lawrence Erlbaum. Retrieved from http://srl.mcgill.ca/publications/2001-HCI.pdf.

[19] Eldokhny, A., \& Drwish, A. (2020). Type of augmented reality presentation via mobile application and its effect on development of cognitive performance and spatial visualization in learning for middle school female students in Kingdom of Saudi Arabia. Scientific Journal of Educational and Qualitative Studies and Research, 1(2), 123-158.

[20] Enyedy, N., Danish, J. A., Delacruz, G., \& Kumar, M. (2012). Learning physics through play in an augmented reality environment. International Journal of Computer-Supported Collaborative Learning, 7(3), 347-378. https://doi.org/10.1007/s11412-012-9150-3.

[21] Fidan, M. \& Tuncel, M. (2018). Augmented reality in education researchers (2012-2017): A content analysis.Cypriot Journal of Educational Science. 13(4), 577-589. https://doi.org/10.18844/cjes.v13i4.3487.

[22] Hamilton, K. \& Olenewa, J. (2010). Augmented reality in education [PowerPoint slides]. Retrieved from http://www.authorstream.com/Presentation/k3hamilton-478823augmented-reality-in-education. 
[23] Ho, S.-C., Hsieh, S.-W., Sun, P.-C., \& Chen, C.-M. (2017). To activate English learning: Listen and speak in real life context with an AR featured U-Learning system. Educational Technology \& Society, 20(2), 176-187. Retrieved from https://www.jstor.org/stable/90002173.

[24] Hughes, J. E., McLeod, S., Brown, R., Maeda, Y., \& Choi, J. (2007). Academic achievement and perceptions of the learning environment in virtual and traditional secondary mathematics classrooms. American Journal of Distance Education, 21(4), 199-214. https://doi.org/10.1080/08923640701595365.

[25] Ibáñez, M. B., Di Serio, A., Villarán, D., \& Kloos, C. D. (2014). Experimenting with electromagnetism using augmented reality: Impact on flow student experience and educational effectiveness. Computers \& Education, 71, 1-13. https://doi.org/10.1016/j.compedu.2013. 09.004.

[26] Karal, H. \& Abdusselam, M. S. (2015). Increased reality. In B. Akkoyunlu, A. Isman \& H. F. Odabasi (Eds.), Education technologies readings. 149-176. Ankara, Turkey: TOJET. Retrieved from https://www.rsearchgate.net/profile/Tuelin_Haslaman/publication/ 303880949_teknoloji_okum lari_2016/links/575a692d08aed884620d2dc2/teknolojiokumalari-2016.pdf\#page $=446$

[27] Kerawalla, L., Luckin, R., Selijefot, S., \& Woolard, A. (2006). Making it real: Exploring the potential of augmented reality for teaching primary school science. Virtual Reality, 10(3-4), 163-174. https://doi.10.1007/s10055-006-0036-4.

[28] Klopfer, E., \& Squire, K. (2008). Environmental detectives - The development of an augmented reality platform for environmental simulations. Educational Technology Research and Development, 56(2), 203-228. https://doi.10.1007/s11423-007-9037-6.

[29] Kuzu, A. (2014). Theoretical foundations of multimedia applications. In O. O. Dursun \& F. H. Odabasi (Eds.), Multi environmental design. 2-33. Ankara, Turkey: Pegem Academy Publications.

[30] Levy, S. (2003). Six factors to consider when planning online distance learning programs in higher education. Online Journal of Distance Learning Administration. 6. Retrieved from https://pdfs.semanticscholar.org/53da/62f2eca6553b85118fadf6c1051d15e5a2ca. pdf? ga=2.226922719.337204078.1593531939-1027690402.1587479758.

[31] Liou, H.-H., Yang, S. J. H., Chen, S. Y., \& Tarng, W. (2017). The influences of the 2D image-based augmented reality and virtual reality on student learning. Educational Technology \& Society, 20(3), 110-121. Retrieved from https://www.jstor.org/stable/26196123.

[32] Lytridis, C., Tsinakos, A., \& Kazanidis, I. (2018). ARTutor-an augmented reality platform for interactive distance learning. Education Sciences, 8(1), 6. https://doi.org/10.3390/educsci8010006.

[33] Morrison, A., Mulloni, A., Lemmela, S., Oulasvirta, A., Jacucci, G., Peltonen, P., Schmalstieg, D., \& Regenbrecht, H. (2011). Collaborative use of mobile augmented reality with paper maps. Computers \& Graphics, 35(4), 789-799. https://doi.org/10.1016/j.cag. 2011.04.009.

[34] Ni, A. Y. (2013). Comparing the effectiveness of classroom and online learning: Teaching research methods. Journal of Public Affairs Education, 19(2), 199-215, http://doi.org/10. $\underline{1080 / 15236803.2013 .12001730}$.

[35] Nurbekova, Z., \& Baigusheva, B., (2020). On the Issue of Compliance with Didactic Principles in Learning using Augmented Reality, International journal of emerging technologies in learning, 15 (15), 121-132, https://doi.org/10.3991/ijet.v15i15.14399

[36] Patrick, S., \& Powell, A., (2009). A summary of research on the effectiveness of K-12 online learning. International Association for K-12 Online Learning. Retrieved from 
https://www.k12.com/sites/default/files/pdf/school-docs/NACOL_ResearchEffectivenesshr.pdf.

[37] Safsouf, Y., Mansouri, K., \& Poirier, F. (2020). An analysis to understand the online learners' success in public higher education in Morocco. Journal of Information Technology Education: Research, 19, 87- 112. https://doi.org/10.28945/4518.

[38] Santos, M. E. C., Chen, A., Taketomi, T., Yamamoto, G., Miyazaki, J., \& Kato, H. (2013) Augmented reality learning experiences: Survey of prototype design and evaluation. IEEE Transactions on learning technologies, 7(1), 38-56. https://doi.org/10.1109/TLT.2013.37.

[39] Saykili, A. (2019). Augmented reality in open and distance learning. In Proceedings of Teaching and Education Conferences (No. 9612271). International Institute of Social and Economic Sciences. Retrieved from https://ideas.repec.org/p/sek/itepro/9612271.html.

[40] Setiawan, A. (2020). Scientific literacy worksheets for distance learning in the topic of Coronavirus 2019 (COVID-19). Reading Academic Articles, 10, 2. https://doi.org/10.31004/edukatif.v2i1.xx.

[41] Shelton, B. E., \& Hedley, N. R. (2002). Using augmented reality for teaching earth-sun relationship to undergraduate geography students. Paper presented at the First IEEE International Augmented Reality Toolkit Workshop. IEEE, Darmstadt, Germany. Retrieved from http://citeseerx.ist.psu.edu/viewdoc/download?doi=10.1.1.116.3323\&rep=rep1\&type=pdf.

[42] Sommerauer, P., \& Müller, O. (2014). Augmented reality in informal learning environments: A field experiment in a mathematics exhibition. Computers \& Education, 79, 5968. https://doi.org/10.1016/j.compedu.2014.07.013.

[43] Viscione, I., \& D'Elia, F. (2019). Augmented reality for learning in distance education: The case of e-sports. Journal of Physical Education and Sport, 19. https://doi.20472050.10.7752/jpes.2019.s5304.

[44] Wei, X., Weng, D., Liu, Y., \& Wang, Y. (2015). Teaching based on augmented reality for a technical creative design course. Computers \& Education, 81, 221-234. https://doi.org/10.1016/j.compedu.2014.10.017.

[45] Wójcik1, M. (2016). Potential use of Augmented Reality in LIS education. Published online: 12, May 2015. http//www. Springer Science+Business Media New York 2015. https://doi.org/10.1007/s10639-015-9399-z.

[46] Yuen, S. C. Y., Yaoyuneyong, G., \& Johnson, E. (2011). Augmented reality: An overview and five directions for AR in education. Journal of Educational Technology Development and Exchange, 4(1), 11. https://doi.10.18785/jetde.0401.10.

[47] Zhang, J., Sung, Y. T., Hou, H. T., \& Chang, K. E. (2014). The development and evaluation of an augmented reality based armillary sphere for astronomical observation instruction. Computers \& Education, 73, 178-188. https://doi.org/10.1016/j.compedu.2014. $\underline{01.003 .}$.

\section{Authors}

Amany Ahmed Eldokhny is an Egyptian Associate Professor and earned a Ph.D. from Ain Shams University in 2013. She works in the Instructional Technology Department, Faculty of Specific Education at Ain Shams University \& King Faisal University in Saudi Arabia. Her areas of interest are e-learning, LMS, infographics, social networks, augmented reality, and the internet of things. She serves as Adviser to the National Centre for Measurement in the KSA and as an external reviewer for the 
scientific journal at King Saud University and for scientific books at the Centre of Translation at KSU. She can be reached at amany.eldokhny@sedu.asu.edu.eg.

Amr Mohammed Drwish is an Egyptian Associate Professor with a Ph.D. from Helwan University (2012). He works in the Instructional Technology Department, Faculty of Education at Helwan University \& King Faisal University in Saudi Arabia. His areas of interest are e-learning, scaffolding learning, infographics, social networks, augmented reality, and web quest. He serves as Adviser to the National Centre for Measurement in the KSA, as an internal reviewer at the scientific journal of King Faisal University, and as program accreditation advisor for postgraduate programs at the Faculty of Education, King Faisal University. He can be reached at Amr_Darwish@edu.helwan.edu.eg.

Article submitted 2020-08-19. Resubmitted 2021-01-18. Final acceptance 2021-01-18. Final version published as submitted by the authors. 